\title{
FICÇÃO, DIÁRIO DE CAMPO E PESQUISA-CRIAÇÃO
}

\author{
Éric le Coguiec \\ $\mathrm{PhD}$. \\ Universidade de Québec em Montreal \\ E-mail: le_coguiec.eric@uqam.ca \\ Tradução: Mônica Fagundes Dantas \\ Professora Adjunta/UFRGS \\ modantas67@gmail.com
}

Abstract

Instrumento de coleta de dados, o diário de campo é amplamente recomendado no campo das ciências sociais, mas também cada vez mais indicado na pesquisa-criação. Supõe-se que esse instrumento metodológico contribua para a realização de uma pesquisa que atenda a certos critérios de cientificidade (Savoie-Zajc, 2003, Mucchielli, 1996). No entanto, alguns pesquisadores apontam dificuldades para se ater à análise e interpretação dos dados (Baribeau, 2005). Sem questionar a utilidade do diário de campo em pesquisa-criação, propõe-se uma concepção ampliada de diário de campo, que se estenda para a ficção.

\section{Palabras claves}

Pesquisa-Criação. Metodologia da Pesquisa. Diário de campo. Ficção
Instrument of data collection, the research diary is not only widely recommended in the social sciences, but it has also been increasingly indicated for Arts Based Researchs. It is assumed that this methodological instrument contributes to the achievement of a research that meets certain scientific criteria (SavoieZajc, 2003 Mucchielli, 1996). However, some researchers point out the difficulties of sticking to the analysis and interpretation of the data (Baribeau, 2005). Without questioning the usefulness of the field diary in creation-research, we propose a broader view of the research diary, which extends to fiction.

Keywords

Arts Based Research. Research Methodology. Research Diary. Fiction 


\section{Introdução}

Instrumento de coletas de dados, o diário de campo é amplamente recomendado no campo das ciências sociais, mas também cada vez mais indicado na pesquisa-criação. Supõe-se que esse instrumento metodológico contribua para a realização de uma pesquisa que atenda a certos critérios de cientificidade (Savoie-Zajc, 2003, Mucchielli, 1996). No entanto, alguns pesquisadores apontam dificuldades para se ater à análise e interpretação dos dados (Baribeau, 2005). Sem questionar a utilidade do diário de campo em pesquisa-criação, proponho uma concepção ampliada de diário de campo, que se estenda para a ficção.

No filme Existenz (1999), do cineasta canadense David Cronenberg, o real, ou ao menos o que se entende por real, é posto em causa (Jean, 1999). Para os protagonistas do filme é muito difícil, ou mesmo impossível, distinguir o que emerge do jogo da realidade quando se introduzem os corpos no universo dos jogos de vídeo virtuais. Ao contrário dos atores, que não conseguem mais saber se eles estão no espaço do jogo ou na realidade, o espectador de Existenz sabe que ele assiste a um filme, ou seja, a uma representação do mundo real, que o leva a refletir sobre a obsessão da modernidade em desenvolver a tecnologia para além dos seus limites, questionando as possibilidades ilimitadas da técnica. A expressão estar mergulhado em um filme descreve muito bem a situação de imersão fictícia vivida pelo espectador posto em um estado de engano perceptivo que atua ao nível pré-atentivo (Schaeffer, 1999). No entanto, a ficção não é sinônimo de fraude, como explica Schaeffer (1999).

[...] a ficção procede certamente através de enganos pré-atentivos, mas seu objetivo não é nos enganar, elaborar fingimentos ou ilusões; os enganos que ela elabora são simplesmente o vetor graças ao qual ela pode atingir sua verdadeira finalidade, que é a de nos engajar em uma atividade de modelisação. (p. 199)

O filme, pelo viés da diversão, elabora uma modelização do real, ao mesmo tempo em que designa uma ferramenta de prospecção que procura explorar os possíveis (Cohn, 2001). Se, na esfera artística, a ficção possibilita um prazer estético, sendo um vetor de conhecimento, como é o caso de Existenz, qual é o lugar reservado aos usos ficcionais na esfera universitária?

Tanto a ficção como objeto de estudo e campo de pesquisa (Goodman, 1968; Schaeffer, 1999; Metz, 1971) quanto os usos da ficção como prática de linguagem na universidade são ainda reservados ao campo das ciência sociais, principalmente no meio universitário anglo-saxão, como indica a quantidade de publicações sobre o tema nos últimos 20 anos (Bagley et Cancienne 2002; Banks 2008; Banks and Banks 1998; Barone and Eisner 2012; Dunlop 2001; Iser 1997; Knowles and Cole 2008; Leavy 2009, 2012; Norris 2009; Viswesaran 1994; Mc Niff 2003). $\mathrm{O}$ uso da ficção em ciências sociais se inscreve notadamente nas reivindicações das formas de escrita como construção sócio-histórica (Richardson et St Pierre, 2005; Denzin et Lincoln 1994, 2000; Ellis et Bochner, 1999, 2000, 2003). Para os pesquisadores que participam do paradigma pós-positivista, os regimes da escrita devem levar em conta a subjetividade do pesquisador e a relação entre pesquisador e seu objeto de estudo (Kulick \& Willson, 1995; Lewin \& Leap, 1996), distinguindo-se assim dos discursos científicos que se pretendem 
neutros, objetivos, universais. Isso significa que os saberes produzidos por esse tipo de pesquisador são historicamente, politicamente e linguisticamente situados e ideologicamente ancorados.

Não obstante esta perspectiva pós-positivista, a pesquisa-criação prestou ainda pouca atenção à questão das práticas de linguagem e das diferentes teorias sóciolinguísticas. No entanto, a pesquisa-criação deveria ser interpelada por essa questão, pois ao pensar o trabalho de criação interpela-se necessariamente as formas do discurso e o lugar que a subjetividade ocupa no discurso. Sem retomar em detalhe às especificidades da pesquisa-criação, é útil lembrar a postura mediana ou híbrida desse tipo de pesquisa que articula teoria e prática. Por muito tempo reservado somente aos teóricos, o discurso sobre as práticas em pesquisa-criação é construído pelos praticantes pesquisadores, a partir do estudo de sua própria prática1.

No domínio das artes, os trabalhos de Valéry e de Passeron contribuíram muito para circunscrever o quadro conceitual da pesquisa-criação (Gosselin, 2006; Laurier, 2004; Le Coguiec, 2006). Valéry, referindo-se às artes da linguagem, postula que o estudo da obra enquanto está sendo feita, que ele nomeia poiética, designa um objeto de estudo em sua completude, que mereceria tanta atenção quanto o estudo da obra acabada. Passeron (1975) estende o conceito de poiética de Valéry às artes em geral e distingue a estética, a qual estudaria as ciências da arte em consumo, das ciên-

1 Englobo sob a expressão "pesquisa-criação" as disciplinas artísticas tais como as artes visuais, a música, o teatro, a dança, a literatura, mas também a arquitetura, o design, a moda, não para simplificar, mas porque, por um lado, as fronteiras disciplinares estão cada vez mais pulverizadas e, por outro lado, para mostrar que todas essas disciplinas tem em comum o fato de articular teoria e prática. cias das estruturas próprias da obra enquanto tal (museologia, cenografia, filmografia, etc.) ${ }^{2}$ e da poiética, a qual estudaria as ciências da arte que se faz, enquanto se faz ${ }^{3}$.

No campo da arquitetura e do design, a pesquisa-criação utiliza largamente um quadro teórico e conceitual oriundo da práxis, da filosofia pragmática (Schön, 1996; Boutinet, 1990) e do pensamento complexo (Morin, 1990; Le Moigne, 1994). Quaisquer que sejam as disciplinas, importa "não reduzir o ato do projeto à dimensão e à fase criativa do ato do projeto" (Findeli, 2007, p.152). Segundo o autor, isso traria por consequência o direcionamento da parte reflexiva do projeto de pesquisa para o mundo interior do pesquisador. Na minha opinião, esse não é bem o caso. Esse tipo de pesquisa realizada por praticantes se caracteriza por uma dupla produção teórica e prática, ancorada no projeto e que explicita, ao mesmo tempo, as condições de elaboração do projeto e a subjetividade do pesquisador. Conduzir uma pesquisa-criação supõe que o pesquisador tome como ponto de partida sua prática - isso é, o campo - a fim de desenvolver uma trajetória reflexiva visando entender o que ele faz sem muitas vezes estar em condições de compreender. Isso significa que o pesquisador, segundo as disciplinas, problematiza, por vezes, o desconhecido (Lancri, 2001).

Ao contrário das abordagens especulativas e hipotético-dedutivas, que propõem a

2 Em artigo traduzido para o português, Passeron (1997) explica que as ciências das artes são “(...) disciplinas que resistem à pertencer à estética e se dedicam, com uma frieza clínica, à anatomia interna de cada corpus histórico de criação, à estrutura própria de cada obra, à semiótica possível de seus elementos, a seus efietos retóricos e à sua estilística, como à hermenêutica necessária a suas interpretações" ( $p$. 106). (N. do T.)

3 No mesmo artigo, o autor ressalta que "(...) a poiética estuda apenas a conduta criadora” (p. 108). (N. do T.) 
construção especulativa de um quadro teórico a partir de teorias existentes e que procedem dedutivamente para aplicar a teoria sobre os dados empíricos e assim explicar os fenômenos observados, a pesquisa-criação é do tipo indutiva e propõe a construção de um quadro teórico a partir dos dados. Para retomar a expressão de Lancri (2001), os conceitos são trabalhados pelos fazeres que, em retorno, trabalham os dizeres. Engajado na sua prática, o pesquisador se entrega a um trabalho reflexivo "em ação" e interpretativo "fora de ação", a fim de explicitar conhecimentos tácitos e implícitos inscritos no fazer. O pesquisador faz o sentido emergir a partir de observações e depois verifica a adequação de suas análises. Esta perspectiva metodológica está, certamente, em sintonia com a Grounded Theory, conceitualizada por Glauser et Srauss (1967) no campo das ciências sociais. Neste contexto de pesquisa, constata-se a importância do diário de campo, instrumento desenhado para assegurar o desenvolvimento de uma conduta reflexiva e para evitar a subordinação da prática à teoria.

Diário de campo e pesquisa

A fim de possibilitar a emergência de uma teoria dos dados empíricos e colocar de lado pré-julgamentos, pré-compreensões, conhecimentos anteriores, o pesquisador mantém um diário de campo, reúne notas de ateliê relativas às condições de elaboração de seu trabalho, aos métodos de criação, aos elementos técnicos, mas também notas relativas ao domínio afetivo, sem prestar tanta atenção às formas de discurso admitidas na universidade.

Esses traços escritos são considerados como memorandos (Schatzman et Strauss, 1973) destinados a serem, em um segundo momento, analisados para embasarem a construção de um quadro teórico. Regra geral, na versão final do texto, aparecem trechos do caderno ou, em anexo, o texto em sua totalidade. O diário é também apresentado como uma ferramenta metodológica indispensável para assegurar a triangulação dos instrumentos de coleta de dados (Mucchielli, 1996).

No entanto, o diário de campo não está isento de críticas. Baribeau (2005, p. 28) nota "que é difícil e exigente manter um diário de campo". No que me diz respeito, baseandome nos diários de campo mantidos pelos estudantes, eu destaco alguns pontos.

Em primeiro lugar, noto que subjetividade do pesquisador em relação com sua atividade de criação se faz pouco presente no diário de campo. Os pensamentos, sentimentos, impressões, emoções do pesquisador inscritos no diário dão conta apenas parcialmente de seu estado de espírito, pois ele é, muitas vezes, constrangido a se calar. Porém o engajamento do pesquisador na sua criação e sua proximidade com o objeto de estudo deveriam suscitar formas variadas de escrita. Ora, o diário de campo se inscreve, muito seguidamente, em uma mitologia cientificista (John Van Maanen, 1991).

Em segundo lugar, em ligação com o primeiro ponto, eu noto que o habitus do pesquisador em pesquisa-criação tende ainda a se calcar no habitus do pesquisador tradicional: abordagens metodológicas, regimes de escrita, distância em relação ao objeto de estudo, etc.

Em terceiro lugar, não tendo mais à sua disposição os modelos de diário de campo e precisando convencer o leitor da veracidade 
dos fatos tendo em vista satisfazer as injunções universitárias, o pesquisador, muitas vezes, inventa dados e recheia seu diário de histórias.

Em quarto lugar, o pesquisador quase não dá conta das condições de elaboração do projeto e tende a importar os conceitos e a aplicá-los aos dados empíricos. Em resumo, o pesquisador está inclinado a imaginar os dados para que eles casem com o quadro teórico. Ora, os dados deveriam ser oriundos de dados empíricos. Eu sempre fico surpreso, quando leio dissertações e teses provenientes de pesquisas-criação, ao constatar como são poucas as observações relacionadas às condições econômicas, políticas, sociais, históricas relacionadas à realização do projeto.

Em quinto lugar, o pesquisador tende a silenciar certos dados que divergem - ou que ele pensa que divergem - das ideias geralmente admitidas pelas regras que regem o campo no qual ele evolui.

Em suma, o pesquisador que efetua uma pesquisa-criação está inclinado a adotar as regras dominantes que regem o mundo universitário e se subscreve a formas de escrita predeterminadas. Ainda que as notas descritivas, as observações, a descrição dos fatos, os eventos, o registro das conversas, etc. sejam designados como dados brutos, muitas vezes eles só têm a aparência de dados brutos.

\section{A pesquisa-criação e a ficção}

Essas observações me levam a pensar que a pesquisa-criação ganharia ao considerar a ficção não como objeto de estudo, mas como objeto praticado pelo pesquisador. Mais especificamente, a ficcionalização do diário de campo permitiria ao praticante pesquisador pensar a escrita como atividade de pesquisa (Richardson, 2000). O uso da ficção permitiria forçar um rompimento em um contexto universitário reconhecido e pré-moldado - restrito? -, com o objetivo de repotencializá-lo, A ficção, longe de ser unicamente de natureza estética, designaria uma astúcia que se infiltra no diário de campo e desconstrói seu formato. Ao invés de relatar fatos, de fazer saber, de testemunhar para não esquecer, de dizer o real de modo claro, a ficção no diário de campo designaria ao mesmo tempo uma modelização criativa e um lugar de construção de conhecimentos. O uso da ficção no diário de campo reenvia a seis perspectivas:

\section{Recobrar a experiência do fazer}

A ficção, ao autorizar o pesquisador a suspender as regras da realidade de modo provisório, estimula o pesquisador a recobrar a experiência do fazer. Mesmo se os eventos relatados são fictícios, não correspondem por exemplo ao desenvolvimento exato da atividade de criação, isso não significa que a experiência não seja real (Tisseron, 2005). O que conta, no final, é aceder novamente à experiência do fazer para ser capaz de nomeá-la.

\section{Explicitar as condições de elaboração do projeto de criação \\ Podendo recorrer à ficção, alguns pesquisa- dores se sentirão mais inclinados a explicitar as condições de elaboração de seu projeto de criação e de atualizar o embasamento histó- rico, cultural e social de suas práticas. Esse exercício de explicitação, habitualmente re- servado ao sociólogo, será efetuado desde o interior da própria prática. Através da ficção, o pesquisador se sentirá liberado das restri-}


ções próprias ao campo e poderá desconstruir um certo número de crenças, indicando, para começar, que a atividade de criação não é uma atividade misteriosa, que todo projeto de criação não é absoluto, mas relativo e que ele ocupa, enfim, um lugar histórico. É claro que essa atividade de desconstrução através da ficção implica paralelamente em um trabalho de auto-desconstrução por parte do pesquisador. Esse exercício de atualização via ficção permitiria compreender a história do campo e do espaço de possibilidades que essa engendra, para retomar a terminologia de Bourdieu (1998).

3. Distanciar-se de uma forma de escrita "neutra"

A criação foi por muito tempo excluída da esfera universitária, somente o discurso sobre as obras era considerado legítimo. Não é de se admirar que a pesquisa sobre as obras e as formas de escrita que Ihe são associadas dominem ainda a pesquisa-criação. A ficção recolocaria em questão um regime de escrita dominante que, longe de ser neutro e universal, é o produto de uma construção sócio-histórica e o fruto de uma luta entre os atores. Como exprime claramente Bourdieu (1991):

(...) ainda que tenha suas próprias leis, transcendentes às consciências e às vontades individuais, a herança cultural, que existe em estado materializado e em estado incorporado (sob a forma de um habitus funcionando como uma sorte de transcendental histórico), só existe e subsiste efetivamente (quer dizer enquanto ativa) na e pelas lutas que tem lugar nos campos de produção cultural (campo artístico, etc.), quer dizer, pelos é par os agentes dispostos e aptos a assegurar a reativação continuada (p. 12).
A ficção constituiria uma astúcia para se libertar de uma forma de escrita canônica e permitiria investir em uma prática de linguagem que se moldaria aos contornos da prática.

\section{Favorecer um distanciamento em rela- ção ao objeto de estudo}

A escrita do diário de campo estendido à ficção favoreceria uma conduta reflexiva, favorecendo um distanciamento em relação ao objeto de estudo necessário para efetuar o trabalho de teorização. Mergulhado na ficção, o pesquisador é conduzido a suspender todo julgamento, nomear o que não está sempre em condições de compreender. Abandonando as condutas habituais, as exigências institucionais, as teorias existentes, o pesquisador não procura analisar seu objeto de estudo, cujo sentido só vai emergir posteriormente (Lancri, 2001). Ele escreve sem realmente seguir um plano, sem perseguir um objetivo preciso, deixando de lado os objetivos aos quais ele tinha se fixado e acolhendo os dados que se apresentam a ele sem rejeitá-los. Pela ficção, o pesquisador chega a se distanciar do fazer e pode tratar-se a si mesmo como um outro (Ricœur, 1990).

\section{Recobrar a língua falada ou vernacular}

O pesquisador imerso na ficção pode se autorizar a escrever à margem das normas de linguagem recomendadas pelo ambiente universitário. Ele pode, por exemplo, recuperar a linguagem das suas origens, com a qual ele sempre se expressou e da qual ele foi obrigado a se distanciar quando entrou na universidade e passou a adotar a "língua da norma", expressão de outro habitus. Essa conversão parcial do habitus originário é, geralmente, o preço a pagar para entrar em um novo campo e a lín- 
gua não escapa dessa situação, como ressalta Eribon (2009), em seu livro Retour à Reims. O autor explica que, para aceder ao status de professor universitário, foi constrangido a desaprender a linguagem própria do meio popular do qual ele se originava e calar suas origens sociais.

Reaprender a falar foi mais do que necessário: esquecer as pronunciações e os rumos das frases erradas, as expressões idiomáticas regionais (não mais dizer que a maçã está "orgulhosa", mas que ela está ácida), corrigir o sotaque do Nordeste e o sotaque popular ao mesmo tempo, adquirir um vocabulário mais sofisticado, construir sequências gramaticais mais adequadas... Em resumo, controlar sempre minha linguagem e minha elocução. (p. 81).

Eribon confirma assim as teses de Bakhtine (1977), Bernstein (1990) e Labov (1972) que mostram que a linguagem não é um sistema autônomo que se desenvolve por ela mesma, mas que existe uma relação entre a estrutura da língua e a estrutura social:

O sentido da palavra é inteiramente determinado por seu contexto. De fato, quanto mais contextos, mais significados possíveis. No entanto, a palavra não cessa de ser uma. Ela não se desagrega em tantas palavras quanto sejam os contextos nos quais ela pode se inserir. É claro que essa unicidade da palavra não é assegurada somente pela unicidade de sua composição fonética, há também unicidade inerente a todos os seus significados. Como conciliar a polissemia da palavra erigida no princípio e sua unicidade (Remysen, 2011)? É desse modo que podemos formular, grosseiramente e de maneira elementar, o problema fundamental da semântica. (Bakhtine, 1977, p. 11)
Os usos da linguagem são sempre contextualizados e situados fisicamente, institucionalmente e historicamente. Utilizar a linguagem vernacular no contexto universitário é ainda percebido, pelo menos fora do âmbito das Ciências Sociais, como a expressão de uma estrutura social inferior. Ter isso como recurso designaria um ato de resistência e a ficção seria uma estratégia para um rompimento. Mas não somente isso, pois ela permitiria também reatar com a alteridade, quer dizer, com o que não é considerado uma prática "normal".

\section{Exprimir uma subjetividade que desafia} os julgamentos dominantes

A existência de uma relação entre a estrutura da língua e o estrato social não deve ocultar a existência de uma relação entre a estrutura da língua e seu papel na construção de identidades sociais e individuais (Leap; Boellstorff, 2004). Mesmo se o paradigma pós-positivista autoriza os pesquisadores a não apagar os posicionamentos identitários e a integrá-los às suas pesquisas (Rabinow, 1977; Tedlock, 1992; Leap, 2004), somos forçados a constatar que articulação entre gênero, sexualidades e linguagem varia segundo as disciplinas e os contextos culturais (Greco, 2014; Boutet; Mainguenau, 2005). Se é possível assumir seu posicionamento identitário em pesquisa-criação, a ausência de estudos sobre esse tema limita os pesquisadores à dimensão ideológica intrínseca à visão binária do gênero.

As análises das práticas linguísticas mostraram que a comunidade gay, para resistir aos processos de normalização e de regulação de gênero e sexualidade de ordem dominante e resistir à marginalização social, criou diversas estratégias linguísticas (Hayes 1981; Leap 1996; Baker 2002; Boellstorff, 2004). A 
comunidade gay afro-americana ressignificou, assim, o léxico (Johnson, 2004). Na Indonésia, os homossexuais falam o que eles chamam bahasa gay (linguagem gay), um fenômeno linguístico baseado na língua oficial da Indonésia (Boellstorff,2004). Essa invenção da língua falada, de natureza política, permite reapropriarse pela linguagem de um espaço de ação (Greco, 2014), criando estruturas de sociabilidade e de troca.

De Rimbaud a Burroughs, a literatura está plena de exemplos de criação de novas formas linguísticas que interrogam a construção e a desconstrução de gênero e sexualidades. Lembremos que, durante o Segundo Império e a Terceira República, para escapar das restrições de ordem judicial e da patologização imposta à sexualidade do mesmo sexo, Rimbaud desenvolveu a metáfora como tática de diversão/subversão para tratar de significantes proibidos (Max Kramer, 2011).

Eu não subentendo aqui que a pesquisacriação rejeite todo posicionamento identitário, mas a ausência de estudos relacioando a pesquisa-criação, os estudos sobre gênero e a sociolinguística não favorece as formas de escrita que levam em conta a construção identitária do pesquisador. Ora, a linguagem, para alguns deles, constitui uma tática de ressubjetificação (De Certeau, 1990; Bucholtz et Hall, 2004; Éribon, 2012).

\section{Conclusão}

A utilização do diário de campo como instrumento de pesquisa não foi suficientemente estudada, mesmo que ele faça parte dos instrumentos metodológicos da pesquisa-criação. No entanto, a crise de uma representação objetiva do saber abriu caminho para formas de escrita variadas - criativas o - que autorizam esse tipo de questionamento. Levando em conta o engajamento do pesquisador nesse tipo de pesquisa, é importante realmente considerar as formas de escrita que dão conta dessa implicação. Longe de favorecer a atividade reflexiva do projeto de pesquisa sobre o mundo interior do pesquisador, a emergência de formas de escrita tornaria mais dinâmica a pesquisa sobre o mundo exterior, isto é, sobre as condições de elaboração do projeto de criação, ainda tão ausentes dos trabalhos de pesquisa. A ficção presente na atividade de criação deveria assim se manifestar na atividade de pesquisa e o diário de campo parece ser um lugar propício para que ela assim opere. Neste momento, o uso da ficção deve ser pensado não como produção textual final, mas como uma estratégia de linguagem para teorizar a prática. A capacidade que a ficção tem de ordenar os eventos em uma trama significativa faz dela uma formidável alavanca para produção de sentidos (Weick, 1995). É claro que todo pesquisador deve demonstrar responsabilidade ética e informar o leitor da passagem fictícia do texto. Como sublinha Schaeffer (1999), é importante respeitar o "contrato da ficção". O leitor deve ser capaz de distinguir o que eu produzo ou percebo como ficção. Esse contrato, que varia em função das culturas e dos contextos constitui uma das condições da filogênese da ficção: sua ancoragem social.

Referencias

AÏT-TOUATI, F. Contes de la lune: essai sur la fiction et la science modernes. Paris: Gallimard, 2011. 
BAGLEY, C., \& CANCIENNE, M. B. Educational research and intertextual forms of (re)presentation: The case for dancing the data. Qualitative Inquiry, v. 2, n. 7, 2001.

BAGLEY, C.; CANCIENNE, M. B. (eds.). Dancing the data. New York: Peter Lang, 2002.

BAKER, P. Polari-the lost language of gay men. Londres: Routledge, 2003.

BAKHTINE, M. Le Marxisme et la philosophie du langage: essai d'application de la méthode sociologique en linguistique. Paris, Éd. de Minuit, 1977.

BANKS, A.; BANKS, S. P. (eds.). Fiction and social research: By ice or fire. Walnut Creek, CA: AltaMira Press, 1998.

BANKS, S. Writing as theory. Handbook of the arts in qualitative research. Londres: Sage, 2008.

BARIBEAU, C. L'instrumentation dans la collecte de données. Recherches Qualitatives. Hors-série, n. 2, p. 98-114, 2005.

BARONE, T.; EISNER, E. W. (eds.). Arts based research. Londres: Sage, 2011.

BERNSTEIN, B. The Structuring of Pedagogical Discourse. London: Routledge, 1990.

BOCHNER, A. P; ELLIS, C. S. Which way to turn?. Journal of Contemporary Ethnography, v. 28, n. 5, p. 485-499, 1999.
BOELLSTORFF, T. Gay language and Indonesia: Registering belonging. Journal of Linguistic Anthropology, v.14, n. 2, p. 248-268, 2004.

BOURDIEU, P. Le champ littéraire. In: Actes de la recherche en sciences sociales, v. 89, p. 3-46, setembro, 1991.

BOURDIEU, P. Les Règles de l'art. Genèse et structure du champ littéraire. Paris: Seuil, 1998.

BOUTET J.; MAINGUENEAU, D. Sociolinguistique et analyse de discours: façons de dire, façons de faire. Langage et société, v. 114, n. 4, p. 15-47, 2005.

BOUTINET, J. Anthropologie du projet. Paris, PUF,1990.

BUCHOLTZ, M., HALL, K. Language and identity. In DURANTI, A. (ed.) A Companion to Linguistic Anthropology. Malden: Blackwell, 2004, pp 268-294.

COHN, D. Le propre de la fiction. Paris: Seuil, 2001.

DE CERTEAU, M. L'invention du quotidien. Paris: Gallimard, 1990.

DENZIN, N. K.; LINCOLN, Y. S. The discipline and practice of qualitative research. In DENZIN, N. K.; LINCOLN, Y. S. (ed.). Handbook of qualitative research, 2000, p. 1-28.

DUNLOP, R. Excerpts from Boundary Bay: A novel as educational research. In NEILSEN, L; A. L. COLE; J. G. (eds.), The art of writing inquiry, Halifax: Backalong Books, 2001, p. 1125. 
ELLIS, C. The ethnographic I: A methodological novel about autoethnography. Walnut Creek, CA: AltaMira Press, 2004.

ELLIS, C. S.; BOCHNER, A. (2000). Autoethnography, personal narrative, reflexivity: Researcher as Subject. Communication Faculty Publications. Paper 91, 2000.

ELLIS, C. S.; BOCHNER, A. P. An introduction to the arts and narrative research: art as inquiry. Qualitative Inquiry, v. 9, n. 4, p. 506-514, 2003.

ERIBON, D. Retour à Reims: Une théorie $d u$ sujet. Paris: Fayard, 2009.

ERIBON, D. Réflexions sur la question gay. Paris: Flammarion, 2012.

FINDELI, A., \& COSTE, A. De la recherchecréation à la recherche-projet: un cadre théorique et méthodologique pour la recherche architecturale. Lieux communs, n. 10, p. 139161, 2007.

FLOWER, L.; HAYES, J. R. A cognitive process theory of writing. College composition and communication, v. 32, n. 4, p. 365-387, 1981.

GLASER, B.G.; STRAUSS, A.L. The Discovery of Grounded Theory: Strategies for Qualitative Research. Chicago, IL : Aldine, 1967.

GOODMAN, N. Languages of art: An approach to a theory of symbols. Indianapolis: Hackett publishing, 1968.
GOSSELIN, P.; LE COGUIEC, E. La Recherche création. Pour une compréhension de la recherche en pratique artistique, Québec, Presses de l'Université du Québec, 2006.

GRECO, L. Les recherches linguistiques sur le genre: un état de l'art. Langage et société, n. 2, p. 11-29, 2014.

HAYES, JJ. Lesbians, gay men and their languages. In J. W. CHESEBRO (ed.), Gayspeak. New York: The Pilgrim Press, 1981, p. 28-42.

HERSKER, A. L.; LEAP, W. Representation, Subjectivity and Ethics in Urban Gay Ethnography. City \& Society, n. 12, p.142-147, 1996.

ISER, W. (1997). The Use of Fiction in Literary and Generative Anthropology: An Interview With Wolfgang Iser Anthropoetics, v. 3 n. 2, 1997/1998.

JOHNSON, P. Mother Knows Best: Black Gay Vernacular and Transgressive Domestic Space. In W. LEAP, W.; T. BOELLSTORFF (eds.). Speaking in Queer Tongues. Globalization and Gay Language. Champaign: University of Illinois Press, 2004, p. 251-278.

KNOWLES, J. G.; COLE, A. L. Handbook of the arts in qualitative research: Perspectives, methodologies, examples, and issues. Londres Sage, 2008.

KRAMER, M. Pour une poétique queer de Rimbaud. Itinéraires, 2011-1/2011, p. 123-136, 2011. 
Recebido em: 28/09/2016 Aprovado em: 03/10/2016 